\title{
Centros de producción e investigación de imágenes en 360 grados: una cartografía de no-ficción de inmersión en la academia iberoamericana
}

\author{
Carolina Gois Falandes \\ Universidade Estadual Paulista, Brasil \\ carolina.falandes@unesp.br \\ https://orcid.org/0000-0001-6639-2121
}

\author{
Denis Porto Renó \\ Universidade Estadual Paulista, Brasil \\ denis.reno@unesp.br \\ https://orcid.org/0000-0003-0837-4261
}

\section{0-degree image production and investigation poles: an immersive non-fiction cartography in Ibero-American academy}

\begin{abstract}
RESUMEN
Dado el potencial de innovación que rodea a las imágenes 360 grados, existe un interés significativo por parte de los investigadores en la búsqueda por comprender las posibilidades narrativas de esta modalidad emergente. En este sentido, los grupos de investigación y laboratorios vinculados a las universidades, que, en su mayoría, investigan las innovaciones comunicacionales, insisten en incluir discusiones sobre esta nueva forma de contar

historias entre sus estudios -algunos de forma más continuada y otros con trabajos ocasionales- tendencia también observada en los experimentos llevados a cabo por grandes empresas de comunicación y tecnología. Así, este estudio busca brindar una cartografía de la no-ficción inmersiva en los países iberoamericanos, señalando centros académicos de producción e investigación de imágenes en 360 grados. Para ello, se apoya en una investigación exploratoria, con un relevamiento bibliográfico y documental. Los resultados confirman el interés de grupos de investigación y laboratorios por seguir las innovaciones mediáticas, un contexto en el que se incluyen imágenes en 360 grados. Sin embargo, debido al carácter interdisciplinario de la mayoría de estos centros y la existencia de medios de difusión obsoletos, la búsqueda de un tema específico se vuelve un desafío. Por tanto, se espera que el mapeo realizado pueda ayudar en el desarrollo de nuevas investigaciones.
\end{abstract}

PALABRAS CLAVE

Cartografía iberoamericana; Grupos de investigación y laboratorios de innovación; Video 360 de no-ficción; Narrativas Complejas; Narrativas inmersivas.

\section{ABSTRACT}

Given the potential for innovation that surrounds 360-degree images, there is a significant interest from researchers in the quest to understand the narrative possibilities of this emerging modality. In this sense, research groups and laboratories linked to universities, which, for the most part, investigate communication innovations, insist on including discussions on this new way of storytelling among their studies - some more continuously and others with occasional work - a trend also observed in the experiments carried out by large communication and technology companies. Thus, this study seeks to provide a cartography of immersive nonfiction in Ibero-American countries, pointing to academic centers for the production and research of 360-degree images. To this end, it is supported by exploratory research, with a bibliographic and documental survey. The results confirm the interest of research groups and laboratories in following media innovations, a context in which 360-degree images are included. However, due to the interdisciplinary nature of most of these centers and the existence of outdated means of dissemination, the search for a specific theme becomes challenging. Thus, it is expected that the mapping performed can help in the development of new research.

\section{KEYWORDS}

Iberoamerican cartography; Research groups and innovation laboratories; Nonfiction 360-degree video; Complex narratives; Immersive storytelling. 


\section{Introducción}

En el contemporáneo hiperconectado es inevitable pensar en el área de la comunicación en asociación con formas innovadoras e híbridas, que evolucionan rápidamente a partir de los avances tecnológicos. Algoritmos, Big Data, diseño de experiencia y realidad virtual son algunos de los elementos imprescindibles en la actualidad para entender las formas de contar historias en el contexto digital. Esas nuevas posibilidades mediáticas han generado transformaciones que afectan al productor y consumidor de contenidos.

Especialmente en el campo de la no-ficción, se ha observado en las últimas décadas una constante reconfiguración de la estructura de las producciones con el objetivo de acercar al público a los hechos. Desde esta perspectiva, se pueden destacar las narrativas en 360 grados, que parecen estar buscando su espacio en los hábitos mediáticos de la mayoría de las personas, a pesar de su gran potencial expresivo e inmersivo. Entre las obras, se pueden ver narrativas contadas desde un solo contenido y otras que componen proyectos más complejos, sustentados en la interactividad y la transmedialidad, brindando innumerables caminos para el usuario. Así, se nota una tendencia de las grandes empresas de comunicación y de tecnología en la exploración de esa modalidad de imagen en sus más variadas aplicaciones en laboratorios de innovación, dada su naturaleza emergente, a ejemplo del BBC Reality Labs (BBC Research \& Development) 1 VR Creator Lab (YouTube)² y Google News Lab (Google) ${ }^{3}$.

Al mismo tiempo, se percibe en el ambiente académico un movimiento de grupos y laboratorios de investigación, que tanto versan sobre las producciones que los medios tienen desarrollado, como en relación con las experimentaciones propias y de sus pares, trayendo reflexiones respecto a los múltiples formatos atribuidos a las imágenes en 360 grados de no-ficción. Los esfuerzos de universidades de todo el mundo en la investigación y experimentación de tecnologías emergentes a través de medialabs demuestran el compromiso de la academia en desarrollar proyectos que puedan facilitar el aprendizaje de los estudiantes, animándolos a realizar nuevos estudios y aplicaciones relacionadas con este campo tecnológico (Vivar, 2012).

Sinónimo de innovación en la comunicación, la exploración de producciones en 360 grados ha sido representada por varias denominaciones, como narrativas inmersivas, realidad virtual y realidad extendida, observándose, sin embargo, una concentración más expresiva de estudios relacionados a contenidos periodísticos, caracterizados bajo la marca periodismo inmersivo. En esa línea de investigación, se puede citar a autoras como Nonny de la Peña, de Estados Unidos de América, Eva
Domínguez-Martín, de España, y Raquel Ritter Longhi, de Brasil, con trabajos de referencia en el área.

En vista del panorama resaltado, en que se percibe movilizaciones en la industria creativa y en el campo académico a favor de solidificar la propuesta de la modalidad de imagen 360 grados y otras innovaciones emergentes, esta investigación busca ofrecer una cartografía de no-ficción de inmersión en países iberoamericanos, ubicando polos de producción e investigación de imágenes en 360 grados en el contexto científico, de modo a medir el nivel de interés de la academia por ese tema y favorecer el proceso de realización de nuevas investigaciones, una vez que serán delimitados centros académicos importantes dedicados a ese universo temático. El análisis se restringe al contexto universitario iberoamericano, que seguramente presenta modelos singulares de investigación y producción relacionados con contenidos en 360 grados de no-ficción, con una significativa representación en el campo de la comunicación. En términos metodológicos, el presente trabajo se apoya en una investigación exploratoria, involucrando relevamiento bibliográfico y documental, teniendo como categorías de análisis cuatro niveles de evaluación apuntados por Vázquez-Herrero, López-García y Lovato (2017) en estudio sobre el laboratorio universitario DocuMedia, de Argentina: institucional, docente, investigador y de producción, siendo que el último nivel será examinado a partir del aspecto de transmedialidad.

Así, este estudio presenta una fotografía del escenario actual de investigaciones en diversos niveles sobre las narrativas audiovisuales en 360 grados de no-ficción a partir de centros académicos de referencia en Iberoamérica, dibujando una sistematización que puede contribuir para una mejor visualización de las iniciativas existentes, y, en consecuencia, facilitar la búsqueda de datos relacionados con este tema.

\section{Marco Teórico}

Entre los objetos que envuelven el universo de la investigación en comunicación digital, las imágenes en 360 grados han recibido una atención significativa de autores de diferentes lugares del mundo. El potencial de innovación de esa modalidad ha despertado una disputa por parte de los investigadores en el intento de describir sus particularidades técnicas, comprender posibilidades narrativas y experimentar el formato. Esto se da en conjunto con los avances tecnológicos que han permitido una relación más cercana con los equipos de producción y edición de contenidos inmersivos, así como la exploración de estas producciones por parte de empresas de medios, grupos de investigación y laboratorios vinculados a las universidades. Estos han sumado a sus áreas de interés debates sobre esta nueva forma de contar historias, estableciendo diálogos con temas que antes se dedicaban, como el periodismo digital, audiovisual y transmedia. Esta percepción se puede confirmar a partir del comentario de Lopezosa, 
Codina, Fernández-Planells y Freixa (2021, p. 2), para quienes la investigación académica "no ha cerrado los ojos" ante innumerables cambios en la forma de informar de los hechos - incluso a través de imágenes 360 grados - y es responsable de la existencia de un "corpus de trabajo muy significativo que examina el significado y alcance de la innovación periodística desde diferentes puntos de vista".

Al tratarse de un tipo de narrativa de la naturaleza emergente, con técnicas no totalmente difundidas y producciones aún alejadas de los hábitos de consumo de los espectadores más habituales (Falandes; Angeluci, 2020), el trabajo de los estudiosos puede ser un pilar importante para el desarrollo de producciones en 360 grados. En este sentido, Català Domènech (2011, p. 192) apunta que los Media Lab (Media Laboratory) e instituciones semejantes son ambientes estratégicos que combinan los esfuerzos de artistas y científicos para probar innovaciones, siendo "un poderoso dispositivo a través del cual la ciencia y el arte contemporáneos se alimentan mutuamente". Al discutir la creación de departamentos de innovación en el ámbito periodístico, Zaragoza-Fuster y García-Avilés (2018, p. 12) afirman que esta práctica se ve favorecida por la necesidad contemporánea de evolución permanente, que ha culminado en la implementación de los medialabs como mecanismo para "canalizar su apuesta por la innovación", basado en la experimentación y lanzamiento de nuevos formatos y lenguajes. Para acercarse al escenario de los laboratorios, Salaverría (2015) realizó, de manera inaugural, un mapeo de laboratorios de innovación impulsado por empresas periodísticas de diferentes partes del mundo, identificando un total de 31 iniciativas en el período de enero de 2015. El autor pudo concluir que la instalación de estos centros en el contexto de los grandes medios informativos refleja una tendencia en expansión, ya que la introducción de novedades a través de ellos acaba despertando constantemente la imitación por parte de "organizaciones informativas de menor envergadura" (Salaverría, 2015, p. 403).

En los términos de Renó y Flores (2018, p. 83), estos espacios innovadores funcionan como "nichos de investigación aplicada y de pruebas para indagar los nuevos fenómenos ofrecidos por la internet y otras tecnologías, como es el caso de las narrativas transmediaticas aplicadas al periodismo". Para ejemplificar las actividades de este sector, los autores mencionan el trabajo de MIT MediaLab, creado en 1985 por el Massachusetts Institute of Technology (MIT), laboratorio cuyas actividades de referencia, que tratan la tecnología como herramienta y objeto de estudio, han incrementado la importancia de los medialabs en las facultades de comunicación. Fortaleciendo ese tipo de iniciativa, Rossetti (2013, p. 64) destaca la necesidad de la innovación se tornar cada vez más un "medio de transformación del conocimiento en mejoría de la calidad de vida de la sociedad". Específicamente sobre el campo de la comunicación, la autora considera que el concepto de innovación se hace más claro cuando se debaten las "interfaces tecnológicas" y los "nuevos medios", abordaje que se ajusta a los intereses de los núcleos de investigación sobre las obras en 360 grados.

Una de las áreas que ha ganado nuevos contornos con la llegada de las imágenes en 360 grados es la no-ficción, que es el tema central de este artículo. En este sentido, es posible señalar estudios que abordan prácticas periodísticas inmersivas, como reportajes y documentales realizados a partir de videos en 360 grados, innovaciones con potencial para acercar al público al contenido informativo a través de un sentido de profundidad e inmersión. Al discutir la innovación en el periodismo, Corrêa y Giacomassi (2018) afirman que el escenario actual requiere una reflexión más allá de las tecnologías de la información, para considerar variables sociales, emocionales y estructurales en el proceso, una posición en línea con el pensamiento de García-Avilés (2021), para quien la innovación periodística necesita expandir su alcance - enfocándose en los aspectos tecnológicos y económicos -, y avanzar hacia la calidad e impacto social de las noticias. Longhi y Lenzi (2017), por su parte, interpretan el fomento de la innovación como una necesidad constante en las prácticas periodísticas, lo que puede influir en la conquista de nuevas generaciones, con costumbres y preferencias distintas a las de generaciones pasadas. Los autores explican que la exploración del periodismo inmersivo en las redacciones, que tuvo su desarrollo exponencial desde 2015, forma parte de una estrategia de innovación y afecta a todos los procesos que involucran la elaboración de noticias, como producción, costos y lenguaje.

Notablemente el periodismo inmersivo presenta un vasto campo a ser explorado por la academia, hecho innegable observando su carácter innovador (Reis y Flores, 2018). Según Reis (2016), las investigaciones pueden involucrar aspectos de la producción y recepción de los contenidos, y, principalmente, el análisis de los modos como esa realidad se relaciona con otras áreas, como ejemplo el periodismo, ciencias de la comunicación y medios digitales, de manera a comprender temas como ética, estructuras narrativas y competencias profesionales, identificando sus implicaciones. Para Cordeiro y Costa (2016, p. 102), el periodismo inmersivo desde un punto de vista tecnológico "se materializa en infografías, producciones de realidad virtual, realidad aumentada, fotos y videos en 360 grados". Los autores sostienen que estos formatos dan al espectador la impresión de estar en el lugar de la noticia, perspectiva alineada con las reflexiones de De la Peña et al. (2010, p. 300), quienes apuntan el periodismo inmersivo como "una manera profundamente diferente de vivir la noticia $y$, por tanto, de entenderla de una forma que sería imposible, sin estar realmente ahí". De acuerdo con Zelcer (2019, p. 28), esta sensación de ser transportado a la escena es lo que califica las imágenes creadas por los dispositivos de realidad virtual como inmersivas, ya que generan en el espectador "el efecto de trasladarse en el tiempo y en el espacio (un estar allí ahora)", una particularidad que, a juicio de Soler-Adillon 
(2017, pp. 2-3), ha vinculado estas tecnologías al concepto de "empatía", ya que sus narrativas permiten al usuario tener la impresión de asumir un "punto de vista concreto". Cabe señalar, sin embargo, que, dentro del campo del periodismo inmersivo y las producciones de no-ficción, esta investigación solamente considerará investigaciones relacionadas con fotos y videos en 360 grados.

También es importante mencionar que, a pesar de la efervescencia de los estudios dedicados al periodismo inmersivo, aún existe una cierta timidez en la exploración de producciones de este tipo, que se extiende a las obras de no-ficción en el contexto general. En la perspectiva de Longhi y Lenzi (2017), esas prácticas narrativas están limitadas a grandes medios de comunicación, lo que puede ser explicado por factores como el alto costo de producción y la falta de acceso del lector a dispositivos para una mayor inmersión en los contenidos.

Con el énfasis dado a las imágenes en 360 grados, se ha observado que investigadores del campo de la no-ficción y los nuevos medios incorporan estos contenidos en sus investigaciones y experimentos relacionados con el transmedia, concepto que según Angeluci es sinónimo de un fenómeno de comunicación innovador, ya que refleja "formas y medios de contar una historia en la época contemporánea" (2016, p. 19). Gifreu-Castells evalúa que con el tiempo y la llegada de los audiovisuales interactivos y transmedia, la no-ficción ha demostrado ser "un campo experimental idóneo para construir y deconstruir discursos, formatos y lenguajes, una disciplina apta para acoger planteamientos creativos de largo alcance e impacto social" (2017, p. 9).

Así, considerando el panorama presentado, que destaca la modalidad de imagen 360 grados como una innovación en el circuito de la comunicación, parece pertinente analizar cómo iniciativas llevadas a cabo en el contexto universitario por grupos de investigación y laboratorios han explorado esta tecnología, a pesar del reconocimiento de que muchas veces las acciones "tienen una vida corta" y tienen una estructura que "varía con rapidez", como señalan Renó y Flores (2018, p. 79). De cualquier forma, los resultados obtenidos pueden apuntar a signos de mayor consistencia en los proyectos pertenecientes a narrativas de 360 grados y sus aproximaciones interdisciplinares.

\section{Metodología}

Con el objetivo de proporcionar una cartografía de la no-ficción de inmersión en países iberoamericanos, se ha intentado relacionar grupos de investigación y laboratorios de innovación universitaria que tengan una dedicación a la investigación y/o experimentación de producciones en 360 grados. Inicialmente, se ha elaborado una relación de iniciativas con base en la propia experiencia de los autores de este artículo sobre el tema y por recomendación de los pares. Para complementar ese listado, fueron consideradas algunas instituciones apuntadas en el Catálogo Inmersivo Iberoamericano 2018 (Trends; Neo Media Lab, 2018), otras encontradas en el estudio realizado por Silva, Cunha y Rodrigues (2020), además de búsquedas en el Google Académico, en el Directorio de Grupos de Investigación de la Plataforma Lattes (CNPq) y en otros espacios de la web, como sitios de universidades, de grupos y en las redes sociales virtuales.

El levantamiento de datos, realizado en el período de 25 de abril y 15 de junio de 2021, ha colectado un total de 29 polos, involucrando 7 países que integran Iberoamérica. Se debe considerar que la selección no contempla la totalidad de los polos de estudio sobre el tema, ya que se desarrolló una investigación exploratoria de forma aleatoria y por conveniencia (Epstein, 2002), mediante el cual se encontraron ejemplos de centros académicos relevantes para la muestra.

Después de la definición de la muestra, esta investigación se ha apoyado en revisiones bibliográficas y documentales, verificando artículos científicos y producciones en 360 grados, de manera que ha sido posible clasificar cada grupo según los cuatro niveles de evaluación propuestos por Vázquez-Herrero, López-García y Lovato (2017): institucional, docente, investigadory de producción.

A través de estas estrategias, ha sido dibujada una cartografía de los polos levantados, ubicándolos por país, institución de educación y nombre del grupo/laboratorio, o mismo del investigador cuando no identificado un grupo específico, apuntando también el año de su última publicación encontrada. Además, se ha desarrollado una cartografía interactiva a partir de la plataforma on-line StoryMapJS ${ }^{4}$, insertando en el mapa iberoamericano las instituciones encontradas en la investigación.

\section{Resultados}

Dada la dificultad de localizar producciones teóricas y prácticas, esta investigación no pretende representar la totalidad de grupos dedicados a investigar narrativas de no-ficción en 360 grados en el contexto iberoamericano. De la misma forma, las informaciones verificadas en el mapeo pueden no incluir el universo de estudios de cada uno de los 29 polos enumerados. Así, este levantamiento se limita a brindar un panorama actual de polos que tienen conexión con esa innovación imagética, lo que puede facilitar el seguimiento de investigaciones sobre el tema e impulsar el intercambio de experiencias entre los núcleos.

El análisis se realizó desde cuatro niveles: institucional, docente, investigador y producción. En cuanto al nivel institucional, el estudio tuvo como objetivo considerar sólo grupos 
vinculados a instituciones educativas, con el fin de delimitar la investigación. De los 29 grupos/laboratorios encontrados, 22 están relacionados con universidades públicas y 7 con universidades privadas. Asimismo, cabe señalar que estos grupos no están destinados exclusivamente al estudio del tema en cuestión, sino que se dedican, en su mayor parte, a investigaciones que involucran innovaciones en la comunicación desde una perspectiva más amplia. Además, hubo estudios que exploran imágenes de 360 grados en otras áreas, como neuromatemática y biología.

De los 22 países que integran lberoamérica, solamente 7 estuvieron representados en esta investigación, a pesar de la insistencia en las búsquedas en la web, lo que muestra vacíos en los estudios científicos en estos lugares y/o errores en su difusión, entre otras circunstancias. El país con mayor representatividad es Brasil, con estudios vinculados a 18 instituciones. En la secuencia, encontramos España (4 instituciones), seguida por Argentina y Portugal, con 2 instituciones cada uno, y Colombia, Ecuador y México con 1 institución cada.

Los polos de investigación y/o producción identificados están representados por participantes que actúan en grupos, laboratorios y otros. Es importante resaltar que ninguno de los nombres utilizados para referirse a los grupos menciona las imágenes en 360 grados. En cuanto a las prácticas actuales de estos grupos, se midieron en base a la fecha del último trabajo, artículo o producción de no-ficción publicada. De esa manera, se encontraron 2 grupos con publicaciones en 2021, 16 grupos con publicaciones en 2020, 7 grupos con publicaciones en 2019, 2 grupos con publicación en 2018 y 2 grupos con publicaciones en 2017. Además de los artículos científicos publicados en revistas y congresos, gran parte de los grupos dan a conocer sus actividades a través de sus propios sitios web y redes sociales. Sin embargo, estos espacios suelen incluir contenidos diversos, referidos a temas de estudio variados, lo que requiere un más expresivo esfuerzo para encontrar datos sobre producciones relacionadas con imágenes en 360 grados. Asimismo, se pudo observar algunos sitios desactualizados, lo que deja en duda la continuidad de los estudios, haciendo necesaria la búsqueda de información por otros medios. En este sentido, es posible recorrer a sitios web personales de algunos investigadores, lo que ha sido identificado en pequeña escala. En el caso de Brasil, es común que las instituciones educativas publiquen en sus sitios web los perfiles de la plataforma Lattes (CNPq) de los investigadores responsables y un resumen con datos sobre sus grupos.

También son destacables las estrategias de los grupos/laboratorios en la promoción de grandes eventos relacionados con el circuito de las narrativas inmersivas. De los 29 centros de investigación analizados, fue posible identificar 11 que par- ticiparon u organizaron este tipo de actividad. Considerando iniciativas de los últimos cuatro años (2018, 2019, 2020 y 2021), es importante mencionar la Muestra BUG, realizada en 2018, vinculada al "BUG LAB", de la UNIRIO y que ha contado con la curadoría de André Paz, Julia Salles y Arnau Gifreu-Castells. El evento "fue la primera y más completa exposición en Brasil sobre el amplio campo de las narrativas interactivas e inmersivas" (Paz, 2019). Además, es oportuno considerar la discusión sobre las imágenes en 360 grados en los congresos online celebrados en 2020. El Congreso Virtual UFBA 2020, realizado en la sede del Grupo de Investigación en Periodismo Online (GJOL), contó con una mesa destinada al periodismo inmersivo. Mientras tanto, el XVI Congreso FORCINE, que ha tenido la participación de integrantes del Laboratorio de Medios Creativos, vinculado al Programa de Postgrado en Medios Creativos de la UFRJ, ha realizado un workshop, un grupo de trabajo y una muestra sobre el tema.

También vale la pena señalar el Festival Internacional de Nuevas Narrativas de No Ficción - Finnof, organizado por la Universidad Nacional de Rosario, por la equipe do \#DCMteam, por la Maestría en Comunicación Digital Interactiva y por la Cátedra Latinoamericana de Narrativas Transmedia, con ediciones en 2020 y 2021. El evento es destinado a promocionar y reconocer producciones de no-ficción, con la realidad virtual entre sus categorías.

Los polos de investigación y producción encontrados están representados en los cuadros a seguir, enumerados de 1 a 7 , cuya orden de presentación representa los países con más expresiva cantidad de polos constatados: Brasil, España, Argentina, Portugal, Colombia, Ecuador y México.

De hecho, el número más expresivo de polos identificados se encuentra en Brasil, pero esto puede estar relacionado con el tamaño del país y su relevancia académica. Además, se observa que 13 grupos presentaron publicaciones en el período de 2019 hasta 2021, lo que revela investigaciones recientes sobre el tema. De igual manera, se ha constatado que, del total de grupos, 11 experimentaron la producción de contenidos en 360 grados, lo que demuestra una creciente investigación aplicada. Algunas de las investigaciones han sido puntuales, pero otras poseen continuidad, como el grupo "Nephijor: Hipermídia e Linguagem", de la Universidad Federal de Santa Catarina, con publicaciones entre los años 2016 y 2020. Otro grupo actuante en Brasil ha sido el "Vidica: Grupo de Pesquisa de Cultura Audiovisual Digital", vinculado a la Pontificia Universidad Católica del Rio Grande do Sul (PUC-RS), con publicaciones entre los años 2017 y 2020. Finalmente, se destaca el grupo "MOBJOR - Grupo de Pesquisa em Jornalismo e Mobilidade", de la Universidad Estatal de Paraíba, con publicaciones entre los años 2017 y 2020. 


\begin{tabular}{|c|c|c|c|c|c|c|}
\hline \multirow[b]{2}{*}{ Grupo/laboratorio } & \multicolumn{4}{|c|}{ Niveles de evaluación: } & \multirow{2}{*}{$\begin{array}{l}\text { Promoción de } \\
\text { eventos/ Festivales }\end{array}$} & \multirow{2}{*}{$\begin{array}{l}\text { Última publicación } \\
\text { sobre el tema } \\
\text { identificada }\end{array}$} \\
\hline & $\begin{array}{l}\text { Institu- } \\
\text { cional }\end{array}$ & Docente & $\begin{array}{l}\text { Investi- } \\
\text { gador }\end{array}$ & $\begin{array}{l}\text { Producción/ } \\
\text { Transmedialidad }\end{array}$ & & \\
\hline LabArteMídia & ECA-USP & Sí & Sí & $\begin{array}{l}\text { Carnaval 4.0 VR } \\
(2020-2021)\end{array}$ & X-Reality (2019/2021) & $\begin{array}{l}\text { Almas y Feitosa } \\
(2020)\end{array}$ \\
\hline $\begin{array}{l}\text { Laboratório de Mídias Cria- } \\
\text { tivas }\end{array}$ & $\begin{array}{l}\text { PPGMC/ } \\
\text { ECO/UFRJ }\end{array}$ & Sí & Sí & $\begin{array}{l}\text { Viva Ouro Preto } \\
\text { VR (2020) }\end{array}$ & $\begin{array}{l}\text { Debate en el XVI Con- } \\
\text { greso Forcine (2020) }\end{array}$ & Maciel (2020) \\
\hline BUG LAB & UNIRIO & Sí & Sí & ------ & Muestra BUG (2019) & $\begin{array}{l}\text { Paz y Gaudenzi } \\
\text { (2019) }\end{array}$ \\
\hline $\begin{array}{l}\text { NephiJor: Hipermídia e Lin- } \\
\text { guagem }\end{array}$ & UFSC & Sí & Sí & $\begin{array}{l}\text { Fotos y videos } \\
360^{\circ} \text { (Instagram) }\end{array}$ & $\begin{array}{l}\text { Proyecto "Fotoli- } \\
\text { vre360" (2018) }\end{array}$ & $\begin{array}{l}\text { Guidotti, Longhi, } \\
\text { Tokasiki y Buzzi } \\
\text { (2020) }\end{array}$ \\
\hline $\begin{array}{l}\text { Laboratório de Narrativa } \\
\text { Hipermídia (HiperLAB) }\end{array}$ & UERN & Sí & Sí & $\begin{array}{l}\text { Micro videos } 360^{\circ} \\
\text { sobre una comu- } \\
\text { nidad (2020) }\end{array}$ & $\begin{array}{l}\text { Eventos para la comu- } \\
\text { nidad y debate online } \\
\text { con un especialista en } \\
\text { producciones } 360^{\circ}\end{array}$ & ----- \\
\hline $\begin{array}{l}\text { Vidica: Grupo de pesquisa de } \\
\text { Cultura Audiovisual Digital }\end{array}$ & PUC-RS & Sí & Sí & $\begin{array}{l}\text { Serie "Malan- } \\
\text { DropsVR" (2018) }\end{array}$ & ----- & $\begin{array}{l}\text { Tietzmann et al. } \\
\text { (2020) }\end{array}$ \\
\hline Narrativas Tecnológicas & UAM & Sí & Sí & ----- & $\begin{array}{l}\text { Conferencias sobre } \\
\text { "Volumetría audiovi- } \\
\text { sual" }\end{array}$ & $\begin{array}{l}\text { Gosciola y Molina } \\
(2020)\end{array}$ \\
\hline $\begin{array}{l}\text { LABCOM - Laboratório de } \\
\text { Convergência de Mídias }\end{array}$ & UFMA & Sí & Sí & $\begin{array}{l}\text { Proyecto Jumper } \\
\text { (2016 - atual- } \\
\text { mente) }\end{array}$ & ----- & Santos (2019) \\
\hline $\begin{array}{l}\text { CODE - Grupo de Pesquisa } \\
\text { em Comunicação, Design e } \\
\text { Tecnologias Digitais }\end{array}$ & Unifesp & Sí & Sí & $\begin{array}{l}\text { Unifesp } 360 \\
\text { (2019) }\end{array}$ & ----- & $\begin{array}{l}\text { Silva y Higuchi } \\
\text { Yanaze (2019) }\end{array}$ \\
\hline $\begin{array}{l}\text { Smart Media \& Users } \\
\text { Research Group / GENEM }\end{array}$ & $\begin{array}{l}\text { USCS / } \\
\text { UNESP }\end{array}$ & Sí & Sí & $\begin{array}{l}\text { Webdoc "Jovens } \\
\text { e as Imagens" } \\
(2020)\end{array}$ & ----- & $\begin{array}{l}\text { Falandes y } \\
\text { Angeluci (2020) }\end{array}$ \\
\hline $\begin{array}{l}\text { O Conhecimento no Jorna- } \\
\text { lismo }\end{array}$ & UEPG & Sí & Sí & $\begin{array}{l}\text { Serie documen- } \\
\text { tal "Agricultura } \\
\text { familiar" (2018) }\end{array}$ & ----- & $\begin{array}{l}\text { Rocha y Rocha } \\
(2021)\end{array}$ \\
\hline $\begin{array}{l}\text { MOBJOR - Grupo de Pes- } \\
\text { quisa em Jornalismo e } \\
\text { Mobilidade }\end{array}$ & UEPB & Sí & Sí & ----- & ----- & Silva et al. (2020) \\
\hline CEPID NeuroMat & USP & Sí & Sí & $\begin{array}{l}3 \text { videos de divul- } \\
\text { gación científica } \\
(2019 / 2020)\end{array}$ & ----- & ----- \\
\hline $\begin{array}{l}\text { GJOL - Grupo de Pesquisa } \\
\text { em Jornalismo On-line }\end{array}$ & UFBA & Sí & Sí & ----- & $\begin{array}{l}\text { Mesa de Periodismo } \\
\text { Inmersivo en congreso } \\
\text { virtual (2020) }\end{array}$ & $\begin{array}{l}\text { Fonseca, Lima y } \\
\text { Barbosa (2019) }\end{array}$ \\
\hline $\begin{array}{l}\text { GEA - Grupo de Estudos } \\
\text { Audiovisuais }\end{array}$ & UNESP & Sí & Sí & ----- & ----- & $\begin{array}{l}\text { Médola y Oliveira } \\
\text { (2017) }\end{array}$ \\
\hline $\begin{array}{l}\text { Ubiqüidade e convergências } \\
\text { tecnologicas na comuni- } \\
\text { cação (CNPq) - Laboratório } \\
\text { Ubilab }\end{array}$ & PUC-RS & Sí & Sí & ----- & ----- & Pasé et al. (2020) \\
\hline Grupo de Pesquisa COMXXI & UFPR & Sí & Sí & $\begin{array}{l}\text { Proyecto "Meu } \\
\text { bicho é legal" } \\
\text { (2017) }\end{array}$ & ----- & $\begin{array}{l}\text { Silva, Bespalhok y } \\
\text { Barboza (2018) }\end{array}$ \\
\hline $\begin{array}{l}\text { Grupo de Pesquisa Ubi- } \\
\text { quidade na Comunicação } \\
\text { (UBICOM) }\end{array}$ & UNAMA & Sí & Sí & ----- & ----- & $\begin{array}{l}\text { Andrade y Sousa } \\
\text { (2019) }\end{array}$ \\
\hline
\end{tabular}

Tabla 1. Brasil. Fuente: Autores 


\begin{tabular}{|c|c|c|c|c|c|c|}
\hline \multirow[b]{2}{*}{ Grupo/laboratorio } & \multicolumn{4}{|c|}{ Niveles de evaluación: } & \multirow[b]{2}{*}{$\begin{array}{l}\text { Promoción de } \\
\text { eventos/ Festivales }\end{array}$} & \multirow{2}{*}{$\begin{array}{l}\text { Última publicación } \\
\text { sobre el tema } \\
\text { identificada }\end{array}$} \\
\hline & $\begin{array}{l}\text { Institu- } \\
\text { cional }\end{array}$ & Docente & $\begin{array}{l}\text { Investi- } \\
\text { gador }\end{array}$ & $\begin{array}{c}\text { Producción/ } \\
\text { Transmedialidad }\end{array}$ & & \\
\hline $\begin{array}{l}\text { DIGIDOC - Grupo de Inves- } \\
\text { tigación en Documentación } \\
\text { Digital y Comunicación } \\
\text { Interactiva. }\end{array}$ & $\begin{array}{l}\text { Universitat } \\
\text { Pompeu } \\
\text { Fabra }\end{array}$ & Sí & Sí & ----- & $\begin{array}{l}\text { II Jornada MAVR } \\
\text { (Mobile Augmented } \\
\text { Virtual Reality) } \\
\text { Audiovisual immersiu: } \\
\text { comunicació, empatia i } \\
\text { interacció (2017) }\end{array}$ & Carles Sora (2018) \\
\hline $\begin{array}{l}\text { E2C VR - Encuentra en } \\
\text { Cuenca }\end{array}$ & $\begin{array}{l}\text { Univer- } \\
\text { sidad de } \\
\text { Castilla-La } \\
\text { Mancha }\end{array}$ & Sí & Sí & $\begin{array}{l}67 \text { videos } 360 \\
\text { grados disponi- } \\
\text { bles en el canal } \\
\text { de YouTube del } \\
\text { laboratorio } \\
\text { (2016-2019) }\end{array}$ & $\begin{array}{l}\text { Realización de cursos, } \\
\text { talleres, entre otros } \\
\text { eventos }\end{array}$ & $\begin{array}{l}\text { Caballero, Bautista } \\
\text { y Casa (2021) }\end{array}$ \\
\hline $\begin{array}{l}\text { Grupo de Investigación NAES } \\
\text { - Narrativas Audiovisuales y } \\
\text { Estudios Socioculturales }\end{array}$ & $\begin{array}{l}\text { Universidad } \\
\text { de Sala- } \\
\text { manca }\end{array}$ & Sí & Sí & $\begin{array}{l}\text { Bajo pluma de } \\
\text { mujer (2019) }\end{array}$ & ----- & $\begin{array}{l}\text { Fidalgo y Ambrósio } \\
(2020)\end{array}$ \\
\hline $\begin{array}{l}\text { Novos Medios Research } \\
\text { Group }\end{array}$ & $\begin{array}{l}\text { Universi- } \\
\text { dade de } \\
\text { Santiago de } \\
\text { Compostela }\end{array}$ & Sí & Sí & ----- & ----- & $\begin{array}{l}\text { Gutiérrez-Ca- } \\
\text { neda, Pérez-Seijo } \\
\text { y López-García } \\
(2020)\end{array}$ \\
\hline
\end{tabular}

Tabla 2. España. Fuente: Autores

En España, han sido identificados cuatro polos de investigación sobre el tema. El país se configura como un centro de referencia en el estudio de narrativas imagéticas de no-ficción en 360 grados. Entre los principales estudiosos, se destaca la investigadora María Isabel Rodríguez Fidalgo, de la Universidad de Salamanca, que ha publicado 16 textos sobre el tema, sea con otros autores o mismo como autora única. Los textos han sido publicados entre los años 2016 a 2020. Además, se destaca el proyecto transmedia "Bajo pluma de mujer: un proyecto sobre la correspondencia femenina a Miguel de Unamuno y Jugo" (2019), donde Fidalgo ha actuado como investigadora principal y ha explorado los videos en 360 grados como parte de la narrativa. También cabe resaltar la importante cantidad de producciones en 360 grados (67) desarrolladas por el grupo E2C VR - Encuentra en Cuenca, de la Facultad de Periodismo de la Universidad de Castilla-La Mancha, que investiga el tema desde 2016.

Argentina es un país con gran relevancia en los estudios sobre audiovisual, especialmente en el tema de no-ficción y nuevas narrativas. Se destaca en el país el grupo \#DCMteam, vinculado a la Universidad de Rosario, con reconocimiento internacional a través de premios a diversas obras. Entre ellas, se puede destacar la producción "De Barrio Somos", de 2018, que explora videos en 360 grados y ha conquistado diversos premios. Otro ejemplo es lo de la Universidad Nacional de Tres de Febrero - UNTREF, donde investigadores del LaIE - Laboratorio Audiovisual de Investigación y Experimentación presentaron trabajos sobre las imágenes en 360 grados. El laboratorio es parte de la Maestría en Periodismo Documental. También es posible observar que la misma universidad, a partir del grupo de Neo Media Lab, ha colaborado con la creación del Catálogo Inmersivo Iberoamericano 2018.

Portugal es otro país con actuación experimental en el video 360 grados. Allá, una de las instituciones que se destaca es la Universidad do Porto, donde se puede reconocer los trabajos de investigación y de producción del investigador António Baía Reis, vinculado a la institución. En su sitio personal ${ }^{5}$, se han encontrado 7 documentales en 360 grados y la indicación a cuatro artículos publicados sobre el tema. En otro caso, se encuentra la Universidad da Madeira, que es autora del proyecto transmedia "Tell a Tail", de 2019, donde el video 360 grados hace parte de la narrativa.

\begin{tabular}{|c|c|c|c|c|c|c|}
\hline \multirow[b]{2}{*}{ Grupo/laboratorio } & \multicolumn{4}{|c|}{ Niveles de evaluación: } & \multirow[b]{2}{*}{$\begin{array}{l}\text { Promoción de } \\
\text { eventos/ Festivales }\end{array}$} & \multirow{2}{*}{$\begin{array}{l}\text { Última publicación } \\
\text { sobre el tema } \\
\text { identificada }\end{array}$} \\
\hline & $\begin{array}{l}\text { Institu- } \\
\text { cional }\end{array}$ & Docente & $\begin{array}{l}\text { Investi- } \\
\text { gador }\end{array}$ & $\begin{array}{l}\text { Producción/ } \\
\text { Transmedialidad }\end{array}$ & & \\
\hline $\begin{array}{l}\text { \#DCMteam - Producciones } \\
\text { Transmedia }\end{array}$ & UNR & Sí & Sí & $\begin{array}{l}\text { De Barrio Somos } \\
\text { (2018) }\end{array}$ & Finnof (2020/2021) & Lovato (2020) \\
\hline $\begin{array}{l}\text { LaIE, NEO MEDIA LAB Y } \\
\text { UNTREF MEDIA }\end{array}$ & UNTREF & Sí & Sí & ----- & NEO Media Lab (2017) & Gobbi (2019) \\
\hline
\end{tabular}

Tabla 3. Argentina. Fuente: Autores 


\begin{tabular}{|c|c|c|c|c|c|c|}
\hline \multirow[b]{2}{*}{ Grupo/laboratorio } & \multicolumn{4}{|c|}{ Niveles de evaluación: } & \multirow{2}{*}{$\begin{array}{l}\text { Promoción de } \\
\text { eventos/ Festivales }\end{array}$} & \multirow{2}{*}{$\begin{array}{l}\text { Última publicación } \\
\text { sobre el tema } \\
\text { identificada }\end{array}$} \\
\hline & Institucional & Docente & $\begin{array}{l}\text { Investi- } \\
\text { gador }\end{array}$ & $\begin{array}{c}\text { Producción/ } \\
\text { Transmedialidad }\end{array}$ & & \\
\hline $\begin{array}{l}\text { Facultad de Ingeniería } \\
\text { (António Baía Reis) }\end{array}$ & $\begin{array}{l}\text { Universidade } \\
\text { do Porto }\end{array}$ & Sí & Sí & $\begin{array}{l}\text { Badedammen } \\
\text { | } 360 \text { video | VR } \\
\text { (2020) }\end{array}$ & --- & $\begin{array}{l}\text { Reis y Coelho } \\
(2020)\end{array}$ \\
\hline $\begin{array}{l}\text { ITI-LARSyS (Laboratory of } \\
\text { Robotics and Systems in } \\
\text { Engineering and Science) }\end{array}$ & $\begin{array}{l}\text { Universidade } \\
\text { da Madeira }\end{array}$ & Sí & Sí & $\begin{array}{l}\text { Proyecto trans- } \\
\text { media "Tell a Tail" } \\
\text { (2019) }\end{array}$ & ----- & Bala et al. (2020) \\
\hline
\end{tabular}

Tabla 4. Portugal. Fuente: Autores

\begin{tabular}{|c|c|c|c|c|c|c|}
\hline \multirow[b]{2}{*}{ Grupo/laboratorio } & \multicolumn{4}{|c|}{ Niveles de evaluación: } & \multirow{2}{*}{$\begin{array}{l}\text { Promoción de } \\
\text { eventos/ Festivales }\end{array}$} & \multirow{2}{*}{$\begin{array}{l}\text { Última publicación } \\
\text { sobre el tema } \\
\text { identificada }\end{array}$} \\
\hline & Institucional & Docente & $\begin{array}{l}\text { Investi- } \\
\text { gador }\end{array}$ & $\begin{array}{l}\text { Producción/ } \\
\text { Transmedialidad }\end{array}$ & & \\
\hline $\begin{array}{l}\text { HiperLab (Laboratorio } \\
\text { Hipermedia) }\end{array}$ & $\begin{array}{l}\text { Universidad } \\
\text { del Valle }\end{array}$ & Sí & Sí & $\begin{array}{l}\text { Caminandar } \\
\text { - Documental } \\
\text { Realidad Virtual } \\
\text { (2017) }\end{array}$ & ----- & $\begin{array}{l}\text { Gómez, Quintana y } \\
\text { González (2020) }\end{array}$ \\
\hline
\end{tabular}

Tabla 5. Colombia. Fuente: Autores

Colombia es tradicional en ese tipo de experimentación, con varias producciones aisladas. En términos de los criterios de esa investigación, se encuentra el Hiperlab (Laboratorio Hipermedia), vinculado a la Universidad del Valle, que ha producido un documental en 360 grados, lanzado en 2017 y que hace parte del proyecto transmedia "Caminandar", en el cual las experiencias y navegaciones complementares se pueden acceder a través de un $\mathbf{e}-b_{0} \mathbf{k}^{6}$ derivado de la investigación llevada al cabo durante cinco años. Sin embargo, hay otros ejemplos de iniciativa sobre el tema, como el Centro Ático de Producción Audiovisual, de la Pontificia Universidad Javeriana de Bogotá, y el Festival Narrar el Futuro, organizado por Alejandro Angel Torres en su séptima edición. Estos ejemplos no han parte de la investigación por no atender a las categorías definidas para la recolección de datos.

En Ecuador, otro país donde hay diversas experimentaciones aisladas sobre el tema, hemos encontrado, a partir de los criterios definidos previamente para la investigación, el webdoc "Quito: el otro turismo", de 2019, derivado de una investigación coordinada por Pablo Escandón Montenegro, vinculado a la Universidad Andina Simón Bolívar. En la obra, junto a otros tipos de contenido, Escandón ofrece diversas fotografías en 360 grados.

Finalmente, el México, destacamos el documental interactivo "MomentMX", de 2017, producido y dirigido por Pablo Martínez-Zárate, fundador del Laboratorio Iberoamericano de Documental. El laboratorio es parte integrante del Departamento de Comunicación de la Universidad Iberoamericana

\begin{tabular}{|c|c|c|c|c|c|c|}
\hline \multirow[b]{2}{*}{ Grupo/laboratorio } & \multicolumn{4}{|c|}{ Niveles de evaluación: } & \multirow[b]{2}{*}{$\begin{array}{l}\text { Promoción de } \\
\text { eventos/ Festivales }\end{array}$} & \multirow{2}{*}{$\begin{array}{l}\text { Última publicación } \\
\text { sobre el tema } \\
\text { identificada }\end{array}$} \\
\hline & Institucional & Docente & $\begin{array}{l}\text { Investi- } \\
\text { gador }\end{array}$ & $\begin{array}{l}\text { Producción/ } \\
\text { Transmedialidad }\end{array}$ & & \\
\hline $\begin{array}{l}\text { Arsquitensis (Pablo Escan- } \\
\text { dón Montenegro) }\end{array}$ & UASB & Sí & Sí & $\begin{array}{l}\text { Webdoc "Quito, } \\
\text { el otro turismo" } \\
\text { (2019) }\end{array}$ & ----- & ----- \\
\hline
\end{tabular}

Tabla 6. Ecuador. Fuente: Autores

\begin{tabular}{|c|c|c|c|c|c|c|}
\hline \multirow[b]{2}{*}{ Grupo/laboratorio } & \multicolumn{4}{|c|}{ Niveles de evaluación: } & \multirow{2}{*}{$\begin{array}{l}\text { Promoción de } \\
\text { eventos/Festivales }\end{array}$} & \multirow{2}{*}{$\begin{array}{l}\text { Última } \\
\text { publicación } \\
\text { sobre el tema } \\
\text { identificada }\end{array}$} \\
\hline & Institucional & Docente & $\begin{array}{l}\text { Investi- } \\
\text { gador }\end{array}$ & $\begin{array}{l}\text { Producción/ } \\
\text { Transmedialidad }\end{array}$ & & \\
\hline $\begin{array}{l}\text { Laboratorio Iberoamericano } \\
\text { de Documental (Pablo Mar- } \\
\text { tínez-Zárate) }\end{array}$ & $\begin{array}{l}\text { Universidad } \\
\text { Iberoameri- } \\
\text { cana }\end{array}$ & Sí & Sí & $\begin{array}{l}\text { Documen- } \\
\text { tal interactivo } \\
\text { MomentMX (2017) }\end{array}$ & ----- & ----- \\
\hline
\end{tabular}

Tabla 7. México. Fuente: Autores 
y ofrece diversos contenidos, entre ellos fotografías em 360 grados.

Sin embargo, no es solamente en la academia donde se puede observar el desarrollo del audiovisual de no-ficción 360 grados. Hay varias otras iniciativas, diversas de ellas en el campo de la industria del entretenimiento, y en ellas los resultados están direccionados al mercado. Uno de los ejemplos exitosos es el Laboratorio de Innovación RTVE, de la Radio y Televisión Española. Ese laboratorio, que tiene como objetivo crear, probar y mantener proyectos construidos a través de las nuevas narrativas, ha producido diversas obras que contemplan no solamente el 360, pero también a ese formato. Dejamos aquí un necesario reconocimiento a esa iniciativa de la televisión pública de España.

\section{Discusión}

La investigación completada aquí demuestra una vocación experimental presente en las universidades, y el potencial que tiene el tema, no solamente en términos experimentales, como también en el campo de la exploración de un formato novedoso, aunque existente hace un par de años. Y en el escenario de las posibilidades, observamos que Iberoamérica es una región fuerte candidata a crear innovaciones el campo del video de no-ficción 360 grados. Esa situación repite otros escenarios, anteriores a la tecnología digital, donde las narrativas cinematográficas de no-ficción también han sido muy bien representadas por artistas iberoamericanos.

Sin embargo, los resultados también demuestran que hay una preocupación real de la academia frente a la búsqueda por nuevas narrativas de no-ficción, de experimentación, además de una visible proximidad con el mercado del audiovisual. De hecho, cuando consideramos los diversos premios recibidos por el equipo de DCMTeam, por ejemplo, confirmamos la idea de proximidad. Si trata de un equipo académico que, a partir de las producciones, no solamente construye un puente entre el mercado y la academia, sino también lleva las miradas a los dos lados. De igual manera, se puede considerar la producción desarrollada por el ecuatoriano Pablo Escandón, un académico que acaba por producir un contenido abierto y de interés social.

Finalmente, y a partir de la mirada aquí presentada, podemos observar el crecimiento, aunque tímido, de los estudios sobre narrativas de no-ficción en Iberoamérica, así como su papel a la hora de ofrecer narrativas de inmersión. Si trata de una estética, un lenguaje, un formato ideal para complementar otras narrativas más complejas, aunque ella, por sí misma, pueda obtener resultados cognitivos ricos en arte, en comunicación y en cognición.

\section{Notas al final}

1. Se puede acceder a la información sobre los proyectos de BBC Reality Labs en este enlace: https://www.bbc.co.uk/rd/projects/360-video-virtual-reality

2. Se puede acceder a la información sobre los proyectos de VR Creator Lab en este enlace: https://vr.youtube.com/community/

3. Se puede acceder a la información sobre los proyectos de Google News Lab en este enlace: https://blog. google/outreach-initiatives/google-news-initiative/how-journalists-can-tell-compelling-stories-using-vr/

4. StoryMapJS. Accesible en https://cutt.ly/ORJvo5g

5. Información disponible en: https://www.antoniobaiareis.com/

6. E-book disponible en: https://libros.univalle.edu.co/index.php/ programaeditorial/catalog/view/265/76/1736-1?fbclid=IWAR06pxeV9GdnMLOD7BMHQhv-1WpOov36hL4-VGnkSADo-YFgRrVvdJHVmQo

\section{Bibliografía}

Angeluci, A. C. B. (2016). 0 estado da arte da pesquisa científica sobre a comunicação transmídia. Em A. C. B. Angeluci. (Ed.), Comunicação Transmídia, (pp. 19-49). ediPUCRS.

Català Domènech, J. M. (2011). A forma do real: introdução aos estudos visuais. Summus.

Cordeiro, W. R. y Costa, L. (2016). Jornalismo imersivo: perspectivas para os novos formatos. Leituras do Jornalismo, 2(6). https://www3. faac.unesp.br/leiturasdojornalismo/index.php/Leiturasdojornalismo/ article/view/114

Corrêa, E. S. y Giacomassi, F. (2018). Inovações no jornalismo para além das tecnologias digitais. Líbero, 21(41). http://seer.casperlibero. edu.br/index.php/libero/article/view/920

De La Peña, N., Weil, P., Lobera, J., Giannopoulos, E., Pomés, A., Spanlang, B., Friedman, D., Sanchez-Vives, M. y Slater, M. (2010). Immersive Journalism: Immersive Virtual Reality for the First-Person Experience of News. Presence: Teleoperators and Virtual Environments, 19(4), 291-301. https://doi.org/10.1162/PRES_a_00005

Epstein, I. (2002). Divulgação científica: 96 verbetes. Pontes.

Falandes, C. G. y Angeluci, A. C. B. (2020). Produção de uma narrativa complexa: as estratégias utilizadas no webdocumentário Jovens e as Imagens - Relatos e Experiências em 360 Graus. Contracampo (UFF), 39(3), 1-20. https://doi.org/10.22409/contracampo.v0i0.42218

García-Avilés, J.A. (2021). Review article: Journalism innovation research, a diverse and flourishing field (2000-2020). Profesional de la Información, 30(1), 1-34. https://doi.org/10.3145/epi.2021.ene.10

Gifreu-Castells, A. (2017). Estrategias participativas y colaborativas en la narrativa factual. Obra Digital, (12), 7-11. https://doi. org/10.25029/od.2017.131.12

Longhi, R. R. y Lenzi, A. (2017). Práticas ciberjornalísticas em Realidade Virtual: inovação e impacto nos processos de produção. Revista FAMECOS, 24(3), ID26828. https://doi.org/10.15448/19803729.2017.3.26828

Lopezosa C., Codina, L., Fernández-Planells, A. y Freixa, P. (2021). Journalistic innovation: How new formats of digital journalism are perceived in the academic literature. Journalism. https://doi. org/10.1177/14648849211033434 
Paz, A. (21 junio 2019). Mostra Bug. bug404. https://bug404.net/ blog/2019/06/21/mostra-bug/

Reis, A. B. (2016). Mundos virtuais e jornalismo imersivo: uma resenha histórica e conceptual. Estudos de jornalismo, 1(6), 100-112. http:// www.revistaej.sopcom.pt/edicao/106

Reis, A. B. y Coelho, A. F. V. C. C. (2018). Virtual reality and journalism. Digital Journalism, 6(8), 1090-1100. https://doi.org/10.1080/21670811 .2018 .1502046

Renó, D. y Flores, J. (2018). Periodismo transmedia. Ria Editorial. http://www.riaeditorial.com/index.php/periodismo-transmedia/

Rossetti, R. (2013). Categorias de inovação para os estudos em Comunicação. Comunicação \& Inovação, 14(27), 63-72. https://doi. org/10.13037/ci.vol14n27.2262

Salaverría, R. (2015). Los labs como fórmula de innovación en los medios. Profesional de la Información, 24(4), 397-404. https://doi. org/10.3145/epi.2015.jul.06

Silva, F. F., Cunha, R. E. S. y Rodrigues, L. C. S. (2020, noviembre 3 al 6). Repercussões do "Jornalismo Imersivo" no Brasil: mapeamento teórico e prático de pesquisas [Presentación de paper]. 18 Encontro Nacional de Pesquisadores em Jornalismo, SBPJor, Brasil. http:// sbpjor.org.br/congresso/index.php/sbpjor/sbpjor2020/paper/viewFile/2622/1427

Soler-Adillon, J. (2017). Tres conceptos clave en medios digitales. Hipertext.net, (15), 1-9. https://raco.cat/index.php/Hipertext/article/ view/329766/420378

Trends, Neo Media Lab. (2018). Catálogo Inmersivo Iberoamericano 2018. TRENDS y UNTREF. https://issuu.com/kevinchavez4/docs/catalogo_inmersivo_iberoamericano_2018

Vázquez-Herrero, J., López-García, X. y Lovato, A. (2017). Transmedia from university: case study of DocuMedia model. 12th Iberian Conference on Information Systems and Technologies (CISTI), 1-6. https:// doi.org/10.23919/CISTI.2017.7976067

Vivar, J. M. F. (2012). La importancia de los medialabs para la investigación aplicada con tecnologías emergentes. Estudio de caso: creación de mashups. Periodismo en red - Congreso internacional, 5-19.

Zaragoza-Fuster, T., y García-Avilés, J. A. (2018). Desarrollo de la innovación periodística en la televisión pública: El caso del RTVE Lab. Hipertext.net, (17), 11-21. https://doi.org/10.31009/hipertext.net.2018. i17.02

Zelcer, M. (2019). Realidad virtual: algunas observaciones acerca de sus pantallas. Hipertext.net, (18), 23-34. https://doi.org/10.31009/ hipertext.net.2019.118.03

\section{CV}

Carolina Gois Falandes. Estudiante de doctorado en Comunicación en la Facultad de Arquitectura, Artes, Comunicación y Diseño de la Universidad Estatal Paulista - FAAC-UNESP (Brasil). Máster en Innovación en Comunicación de Interés Público de la Universidad Municipal de São Caetano do Sul (PPGCOM-USCS). Licenciada en Comunicación Social - Título en Periodismo (USCS). Licenciada en Cine y Televisión en el Centro Audiovisual de São Bernardo do Campo (CAV). Es investigadora del SMU - Smart Media \& Users Research Group y participante del GENEM - Grupo de Estudios sobre Nueva Ecología de los Medios. Investiga temas relacionados con la cultura digital, tecnologías en educación e innovaciones en el campo de la imagen, con énfasis en narrativas audiovisuales interactivas y 360 grados.

Denis Porto Renó. Periodista y fotógrafo, es Libre-Docente en Ecología de los Medios y Narrativas Imagéticas por la Universidad Estatal Paulista - UNESP (Brasil) e Investigador Becario Productividad PQ2 - CNPq. Es docente en la Universidad Estatal Paulista - UNESP, además de profesor honorífico en la Universidad Complutense de Madrid (España) y profesor visitante en la Universidad Nacional de Rosario (Argentina) y en la Universidad Técnica Particular de Loja - UTPL (Ecuador). Es Director Académico de la Cátedra Latinoamericana de Narrativas Transmedia e Investigador Líder del GENEM - Grupo de Estudios sobre Nueva Ecología de los Medios.

\section{осм Observatorio de Cibermedios}

El Observatorio de Cibermedios es una producción del Grupo de Investigación en Documentación Digital y Comunicación Interactiva (DigiDoc) del Departamento de Comunicación de la Universitat Pompeu Fabra.

El Observatorio de Cibermedios (OCM) forma parte del proyecto del Plan Nacional "Narración interactiva y visibilidad digital en el documental interactivo y el periodismo estructurado". RTI2018-095714-B-C21 (MINECO/FEDER), Ministerio de Ciencia, Innovación y Universidades (España). 